УДК 556.314

\title{
ГУМИНОВЫЕ ВЕЩЕСТВА В ПРИРОДНЫХ ВОДАХ НАРЫКСКО-ОСТАШКИНСКОЙ ПЛОЩАДИ (КУЗБАСС)
}

\author{
Лепокурова Олеся Евгеньевна ${ }^{1,2}$, \\ LepokurovaOY@ipgg.sbras.ru
}
Домрочева Евгения Витальевна ${ }^{1}$, DomrochevaYV@ipgg.sbras.ru

1 Томский филиал Института нефтегазовой геологии и геофизики им. А.А. Трофимука СО РАН, Россия, 634021, г. Томск, пр. Академический, 4.

2 Национальный исследовательский Томский политехнический университет, Россия, 634050, г. Томск, пр. Ленина, 30.

\begin{abstract}
Актуальность работы. Растворенное органическое вещество почти всегда присутствует в водах и играет важную роль в формировании их химического состава, при этом до недавнего времени ему уделялось незаслуженно мало внимания. Для Кузнецкого бассейна изучение растворенного органического вещества очень важно в связи с наличием угольных отложений, что обуславливает региональную специфиику нагрузок на водные системы.

Цель: изучить особенности распределения растворенного органического вещества в поверхностных и подземных водах региона.

Методы. Химический и органический состав воды определялись стандартными методами в Проблемной научноисследовательской лаборатории гидрогеохимии Томского политехнического университета: органический углерод (Сорг) методом высокотемпературного каталитического окисления, перманганатная окисляемость, химическое потребление кислорода, биохимическое потребление кислорода - методами титрования. Определение фуульвокислот и гуминовых кислот проводилось методом титрования по учету бихромата, расходуемого на окисление углерода фрульвогуминовых кислот.

Результаты и выводы. Приведены новые данные по показателям растворенного органического вещества и концентрациям фульвокислот и гуминовых кислот в речных, озерных и подземных водах Нарыкско-Осташкинской площади Кузбасса. Показано, что во всех водах в составе гуминовых веществ преимущественно распространены фуульвокислоты, от 69 до 100 \%, а гумусовые имеют подчиненное значение. Подземные воды зоны активного водообмена отличаются минимальными значениями всех показателей растворенного органического вещества $\left(\mathrm{C}_{\text {орг, }}\right.$ перманганатная окисляемость, химическое потребление кислорода, биохимическое потребление кислорода) и относительно неоднородным составом гуминовых веществ. Речные и озерные воды отличаются более однотипным составом гуминовых веществ и узким интервалом значений показателей растворенного органического вещества, несмотря на различия в химическом составе и рН. Воды зоны затрудненного водообмена в пределах угольных отложений на глубинах 400-1200 м отличаются наибольшими показателями растворенного органического вещества и относительно однородным составом фульвокислот и гуминовых кислот. На первом этапе исследований установлено отсутствие связи концентрации органики с соленостью и химическим составом всех вод, рН и глубины.
\end{abstract}

\section{Ключевые слова:}

Фульвокислоты, гуминовые кислоты, природные воды, угленосные отложения, Кузбасс.

\section{Введение}

Растворенное органическое вещество (РОВ) почти всегда присутствует в водах и играет важную роль в формировании их химического состава, при этом до недавнего времени ему уделялось незаслуженно мало внимания. Однако в последние десятилетия появилось много работ и накопились новые данные о РОВ [1-15], в том числе активно обсуждается участие органических веществ в комплексообразовании и, соответственно, в миграции химических элементов [16-26]. Кроме формирования органоминеральных комплексов, важная функция РОВ как кислотной составляющей в нейтрализации щелочности, образующейся при гидролизе пород с образованием основного аниона для вод верхней зоны - гидрокарбонат-иона $\left(\mathrm{HCO}_{3}{ }^{-}\right)$.

При интерпретации содержаний РОВ используются такие количественные характеристики, как концентрация органического углерода $\left(\mathrm{C}_{\text {орг }}\right)$, а также азота $\left(\mathrm{N}_{\text {орг }}\right)$ и фосфора $\left(\mathrm{P}_{\text {орг }}\right)$. Первая считается наиболее точной для вод. Кроме того, используются показатели окисляемости - перманганатной (ПО) и би- хроматной, а также величины, аппроксимированные с предыдущими, - химическое потребление кислорода (ХПК), биохимическое потребление кислорода $\left(Б^{-} К_{5}\right)$ и другие (в мгО/л или $\mathrm{MrO}_{2} /$ л).

Показатель ПО определяет количество кислорода, потребляемое при окислении пробы воды раствором перманганата калия в серной кислоте. Количество кислорода, необходимое для химического окисления содержащихся в воде органических и неорганических веществ, характеризует ХПК. Израсходованное количество кислорода на аэробное биохимическое окисление нестойких органических соединений в воде под действием микроорганизмов за 5 суток дает показатель БПК. . Регламентируются [27-29] только показатели ПО, ХПК и БПК. В зависимости от целей водопользования предельно-допустимые их концентрации (ПДК) варьируют от 4-5, 15-30 мгО/л и $2-4 \mathrm{MrO}_{2} /$ л соответственно.

Также в водах можно исследовать индивидуальные органические соединения, такие как различные органические кислоты (уксусная, муравьиная и др.), 
различные ароматические углеводороды (бензол, тулуол и др.). Однако, как правило, их концентрации очень низки, что затрудняет их определение [30]. Поэтому часто количественно определяют не индивидуальные, а группы соединений, например, битумы, смолы, гуминовые вещества и др.

Как правило, наибольшее количество РОВ (до 80 \%) приходится на гуминовые вещества (ГВ). Они представляют собой темно-коричневые соединения, формирующиеся в почвенном слое в процессе химического и биохимического разложения растений. Среди ГВ выделяют высокомолекулярные соединения сложного строения - это гуминовые (ГК) и фульвокислоты (ФК). ФК более светлые по окраске, чем ГК, в них содержится меньшее количество углерода, их можно рассматривать либо как продукты разложения ГК, либо как продукты разложения их предшественников [31]. Поверхностные воды разных природно-климатических зон характеризуются различным соотношением ФК и ГК, определяемых спецификой почв [18]. Для подземных вод это соотношение не так явно, источником органики здесь кроме почвы выступают горные породы, а также торф, уголь, горючие сланцы, залежи нефти и др.

Наличие в Кузнецком бассейне угольных отложений и объектов угольного комплекса обуславливает региональную специфику нагрузок на водные системы. Поэтому перед авторами была поставлена задача изучить особенности распределения РОВ в поверхностных и подземных водах региона. Более всего для этих целей подходит Нарыкско-Осташкинская площадь Ерунаковского района Кемеровской области, наиболее перспективная для добычи угольного метана [32]. Благодаря начатому в последние годы бурению, здесь появилась возможность для отбора подземных вод, в том числе глубоких, в пределах угольных пластов.

\section{Методы исследований}

Экспедиционные работы проводились в летнеосенний период (июль, август, октябрь) 2012-2013 гг. сотрудниками ТФ ИНГГ СО РАН в ходе совместных работ с ООО «Газпром добыча Кузнецк» по изучению гидрогеологии, гидрогеохимии и экологии площадей потенциальной промышленной добычи угольного метана в Кузбассе. Всего было отобрано 68 проб, из них: 4 озерных, 13 речных, 51 подземных вод (рис. 1). Однако не во всех точках анализировался полный набор органических показателей.

Непосредственно на месте измерялись температура воды, электропроводность, $\mathrm{pH}$, Eh с использованием прибора Water Test фирмы Наnпа и концентрации быстроизменяющихся компонентов $\left(\mathrm{CO}_{2}, \mathrm{CO}_{3}{ }^{2-}\right.$, $\left.\mathrm{HCO}_{3}^{-}, \mathrm{Fe}^{2+}, \mathrm{Fe}^{3+}\right)$. Пробы воды на РОВ отбирались в пластиковую и стеклянную тары и сразу доставлялись в аккредитованную Проблемную научноисследовательскую лабораторию гидрогеохимии ТПУ

Определения $\mathrm{C}_{\text {орг }}$ выполняли методом высокотемпературного каталитического окисления соединений углерода до диоксида углерода на анализаторе Liquid TOC компании Elementar с детектором инфракрасного излучения. ПО, ХПК, БПК 5 определялись стандартными методами титрования.

Определение ФК и ГК проводилось методом титрования по учету бихромата, расходуемого на окисление углерода фульвогуминовых кислот, растворенных в воде по уравнению:

$$
\begin{gathered}
3 \mathrm{C}+2 \mathrm{~K}_{2} \mathrm{Cr}_{2} \mathrm{O}_{7}+8 \mathrm{H}_{2} \mathrm{SO}_{4}= \\
=2 \mathrm{Cr}_{2}\left(\mathrm{SO}_{4}\right)_{2}+2 \mathrm{~K}_{2} \mathrm{SO}_{4}+8 \mathrm{H}_{2} \mathrm{O}+3 \mathrm{CO}_{2}+3 \mathrm{e},
\end{gathered}
$$

где $3 \mathrm{C}^{0}+4 \mathrm{Cr}^{6+} \rightarrow 4 \mathrm{Cr}^{3+}+3 \mathrm{C}^{4+} \rightarrow \mathrm{Cr}^{6+} \rightarrow \mathrm{Cr}^{3+}$.

Окисление происходит в сильнокислой среде и сопровождается восстановлением шестивалентного хрома в трехвалетный. Избыток бихромата оттитровывается солью Мора.

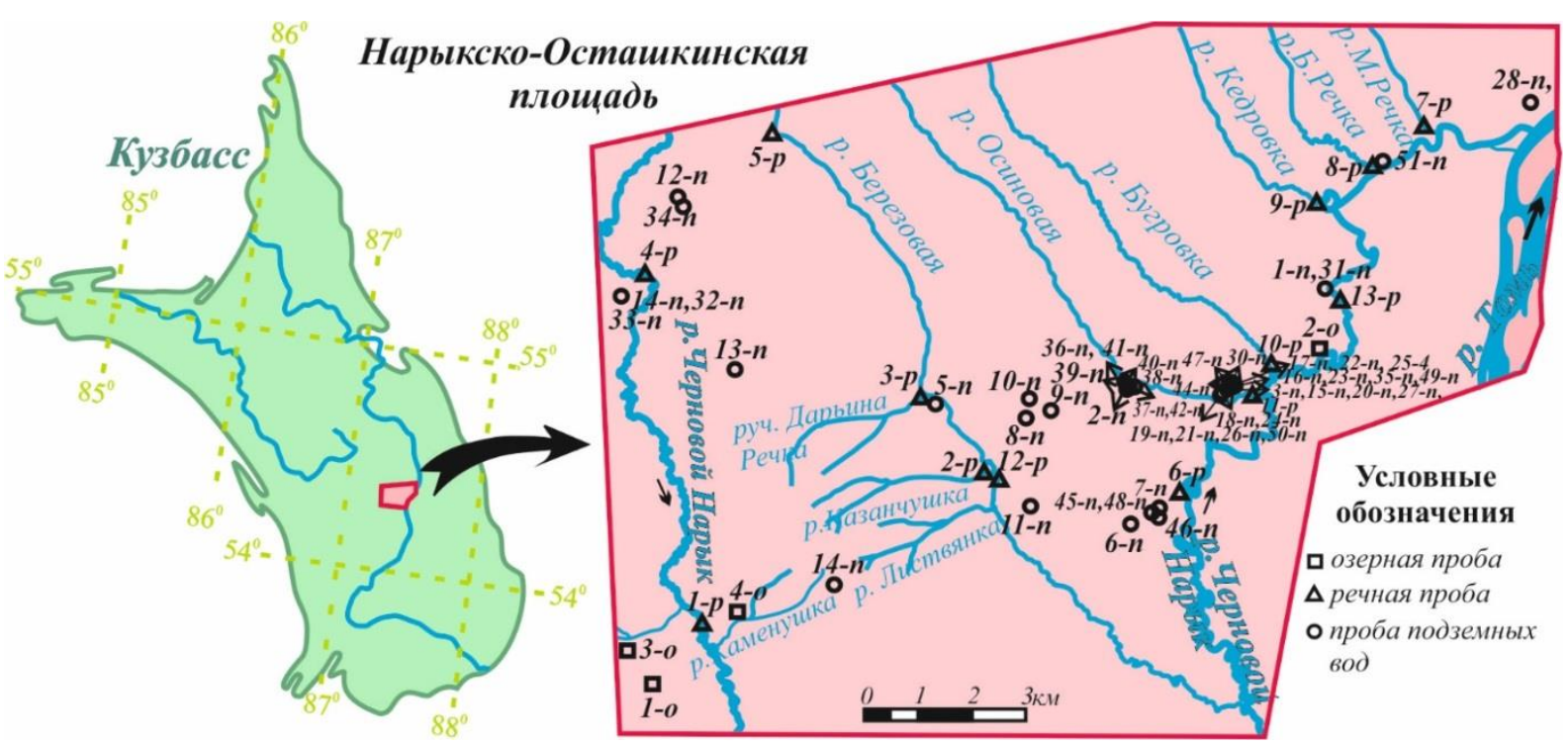

Pис. 1. Схема расположения пунктов опробования природных вод

Fig. 1. Scheme of arrangement of natural water sampling 


\section{Объект исследований}

Исследуемая площадь расположена в центральной части Кузнецкого угольного бассейна (рис. 1). Данная брахисинклинальная структура сложена в подавляющей части разреза пермскими угленоснотерригенными отложениями, представленными песчаниками, аргиллитами и алевролитами с включением до 50 угольных пластов, и разбита тектоническими нарушениями. Выше распространены безугольные триасовые и юрские с невыдержанными маломощными пластами угля отложения. Коренные породы сверху покрыты маломощными рыхлыми отложениями кайнозойского возраста, представленными глинами, суглинками и гравийно-галечниками.

В свое время данную территорию в гидрогеологическом отношении детально изучали такие исследователи, как Г.М. Рогов, Д.С. Покровский, В.К. Попов, Г.А Плевако и др. [33-36]. Однако в последние годы с бурением новых скважин появилась возможность получения новых гидрогеохимических данных, некоторые из которых представлены в работах [37-40]. Кратко можно охарактеризовать исследуемую территорию следующим образом: 1) инфильтрационный характер питания подземных вод, 2) степень закрытости гидрогеологической системы определяется безугольными отложениями, обладающими низкими фильтрационными свойствами, 3) прямая вертикальная гидродинамическая зональность, в соответствии с которой по интенсивности водообмена выделяются две зоны: активного (мощностью 150-300 м) и замедленного водообмена (нижнюю границу пока провести невозможно), 4) прямая вертикальная гидрогеохимическая зональность, в соответствии с которой воды зоны активного и замедленного водообменов отличаются по химическому и газовому составу.

\section{Результаты исследования}

Результаты исследования РОВ в природных водах территории представлены в таблице. Ниже опишем отдельно каждый объект.

Озерные воды и воды прудов-отстойников. Это пресные (соленость 0,1-0,8 г/л) в основном щелочные (рН от 8 до 9,4), исключение составляет заболоченное озеро (pH 6,7), гидрокарбонатные кальциевые, в одном пруду - гидрокарбонатно-сульфатные (название дается от большего к меньшему) кальциевые, воды.

Наибольшими показателями РОВ отличается заболоченное озеро (№ 2-о) с максимальными для данных вод показателями $\mathrm{C}_{\text {орг }}(15,3$ мг/л), ПО (19,6 мгО/л), ХПК (63,15 мгО/л), БПК (1,71 мгО $2 /$ л). Для остальных озер эти показатели ниже и варьируют в пределах $\mathrm{C}_{\text {орг }}$ от 4,1 до 8,5 мг/л, ПО от 4,5 до 5,9, ХПК от 11,6 до 44,3 1,49 мгО/л и БПК от 0,06 до $1,49 \mathrm{MrO}_{2} /$ л. Превышение относительно ПДК характерно для ХПК и ПО.

Гуминовые вещества представлены в основном фульвокислотами от 83,6 до 95,7 \% (от 7,9 до 31,8 мг/л), гуминовые кислоты имеют подчиненное значение от 4,2 до 16,3 \% (0,6-1,5 мг/л).
Речные воды. В пределах исследуемой площади отобраны пробы вод из рек Черновой Нарык (основная водная артель), Казанчушка, Дарьина Речка, Березовая, Большая речка, Осиновка и безымянный ручей (рис. 1). Воды пресные (соленость 0,3-0,6 г/л) слабощелочные и щелочные ( $\mathrm{pH}$ от 7,6 до 8,9) гидрокарбонатные кальциевые.

Таблица. РОВ в природных водах территории

Table. Dissolved organic matter (DOM) in natural water

\begin{tabular}{|c|c|c|c|c|c|c|c|c|}
\hline \multirow{2}{*}{ № } & TDS & $\mathrm{pH}$ & $\begin{array}{l}\mathrm{C}_{\text {opr }} \\
\text { DOC }\end{array}$ & $\begin{array}{l}\text { ПО } \\
\text { OD }\end{array}$ & $\begin{array}{l}\text { ХПК } \\
\text { COD }\end{array}$ & $\begin{array}{l}\text { БПК } \\
\text { BOD }\end{array}$ & $\begin{array}{l}\Phi K \\
\text { FA's }\end{array}$ & $\begin{array}{r}\Gamma K \\
\text { HA's } \\
\end{array}$ \\
\hline & $\begin{array}{l}\mathrm{M \Gamma} / \mathrm{J} \\
\mathrm{mg} / \mathrm{L}\end{array}$ & - & $\begin{array}{l}\mathrm{M \Gamma} / \mathrm{\pi} \\
\mathrm{mg} / \mathrm{L}\end{array}$ & \multicolumn{2}{|c|}{$\begin{array}{c}\mathrm{M \Gamma O} / \mathrm{I} \\
\mathrm{mgO} / \mathrm{L}\end{array}$} & $\begin{array}{l}\mathrm{MrO}_{2} / \mathrm{I} \\
\mathrm{mgO}_{2} / \mathrm{L}\end{array}$ & \multicolumn{2}{|c|}{$\begin{array}{c}\mathrm{M} / \mathrm{J} \\
\mathrm{mg} / \mathrm{L}\end{array}$} \\
\hline \multicolumn{9}{|c|}{ Озерные воды/Lake water } \\
\hline $1-0$ & 635 & 7,8 & 5,44 & - & 11,8 & 1,49 & 10,02 & 1,51 \\
\hline $2-\mathrm{o}$ & 136 & 6,7 & 15,30 & 19,60 & 63,1 & 1,71 & 31,80 & 1,45 \\
\hline $3-0$ & 222 & 9,4 & 4,10 & 4,52 & 39,9 & 0,06 & 7,87 & 0,88 \\
\hline 4-o & 862 & 8,0 & 8,46 & 5,88 & 44,3 & 0,59 & 17,82 & 0,61 \\
\hline \multicolumn{9}{|c|}{ Речные воды/River water } \\
\hline $1-\mathrm{p}$ & 317 & 8,1 & 2,4 & - & 126,50 & 1,66 & 4,84 & 0,34 \\
\hline $2-p$ & 334 & 7,6 & 7,77 & - & 16,80 & 2,57 & 16,21 & 0,68 \\
\hline $3-p$ & 370 & 8,2 & 6,22 & - & 9,89 & 3,15 & 12,59 & 0,85 \\
\hline 4-p & 341 & 8,2 & 8,25 & - & 11,14 & 1,14 & 17,28 & 0,68 \\
\hline $5-p$ & 381 & 7,9 & 6,85 & - & 8,86 & 1,54 & 14,19 & 0,68 \\
\hline $6-p$ & 421 & 8,4 & 8,98 & - & 8,60 & 1,47 & 17,8 & 1,51 \\
\hline $7-p$ & 341 & 8,0 & 8,42 & - & 11,05 & 1,86 & 17,18 & 1,04 \\
\hline 8-p & 378 & 8,1 & 36,64 & - & 14,10 & 1,41 & 78,83 & 1,38 \\
\hline 9-p & 412 & 8,0 & 6,92 & - & 13,90 & 1,97 & 14,56 & 0,52 \\
\hline $10-p$ & 403 & 7,9 & 7,94 & - & 17,65 & 0,66 & 16,60 & 0,68 \\
\hline $11-p$ & 408 & 8,4 & 6,33 & - & 22,75 & 1,54 & 11,95 & 1,54 \\
\hline $12-p$ & 387 & 8,2 & 5,41 & - & 20,90 & 1,87 & 10,80 & 0,85 \\
\hline $13-p$ & 698 & 8,9 & 6,81 & 2,64 & 33,90 & 0,22 & 14,21 & 0,60 \\
\hline
\end{tabular}

Подземные воды (наиболее информативные пробы)

Ground water (the most informative samples)

\begin{tabular}{|c|c|c|c|c|c|c|c|c|}
\hline $1-\Pi$ & 459 & 7,2 & 1,91 & - & 4,03 & 0,69 & 3,68 & 1,03 \\
\hline $2-\Pi$ & 480 & 8,0 & 2,69 & 0,20 & 24,70 & 0,22 & 4,07 & 1,42 \\
\hline $4-\Pi$ & 569 & 7,7 & 2,34 & 0,44 & 24,40 & 0,05 & 4,93 & 0,17 \\
\hline $5-\Pi$ & 483 & 8,1 & 4,14 & 0,16 & 31,90 & 1,41 & 8,12 & 0,76 \\
\hline $6-\Pi$ & 625 & 7,6 & 1,91 & 0,40 & 26,80 & 0,70 & 3,77 & 0,34 \\
\hline 8 -п & 711 & 7,3 & 3,36 & 0,92 & 27,10 & 1,20 & 6,60 & 0,61 \\
\hline $9-\Pi$ & 548 & 7,4 & 2,98 & 0,12 & 25,30 & 1,15 & 5,79 & 0,59 \\
\hline $10-\Pi$ & 601 & 7,0 & 1,90 & 4,00 & 25,80 & 0,30 & 3,38 & 0,62 \\
\hline $12-\Pi$ & 769 & 7,4 & 1,08 & 0,92 & 24,10 & 0,62 & 1,98 & 0,30 \\
\hline $13-\Pi$ & 463 & 7,6 & 3,20 & 0,08 & 22,80 & 0,59 & 5,91 & 0,87 \\
\hline $14-\Pi$ & 475 & 7,9 & 1,56 & 0,16 & 21,60 & 0,57 & 3,05 & 0,29 \\
\hline $15-\Pi$ & 503 & 7,9 & 4,34 & - & 4,12 & 0,09 & 8,82 & 0,57 \\
\hline $25-\Pi$ & 455 & 8,1 & 2,11 & 0,56 & 2,85 & 0,45 & 3,61 & 1,64 \\
\hline $28-\Pi$ & 929 & 7,5 & 7,37 & - & 7,24 & 1,38 & 14,65 & 6,68 \\
\hline $29-\Pi$ & 780 & 7,1 & - & 0,25 & 5,21 & - & 41,68 & 0,51 \\
\hline $30-\Pi$ & 1474 & 7,9 & 3,56 & - & 41,90 & 2,33 & 7,30 & 3,32 \\
\hline $31-\Pi$ & 1499 & 8,3 & - & 0,48 & 19,00 & - & 20,13 & 0,65 \\
\hline $35-\Pi$ & 9333 & 7,2 & - & 6,08 & 25,70 & - & - & - \\
\hline $36-\Pi$ & 10990 & 8,2 & 17,51 & - & - & 2,31 & 37,40 & 17,00 \\
\hline $37-\Pi$ & 10019 & 7,8 & 36,31 & - & - & 1,84 & 78,41 & 35,64 \\
\hline $38-\Pi$ & 17355 & 7,8 & 16,91 & - & - & 0,73 & 36,23 & 16,47 \\
\hline $39-\Pi$ & 11946 & 8,3 & 13,80 & - & - & 2,09 & 29,16 & 13,25 \\
\hline $41-\Pi$ & 10845 & 8,7 & 9,15 & 2,28 & 81,0 & - & 20,13 & 0,65 \\
\hline $43-\Pi$ & 12680 & 8,2 & - & 3,52 & 101,0 & - & 41,68 & 0,51 \\
\hline $44-\Pi$ & 11075 & 8,4 & 12,79 & - & - & 3,83 & 27,92 & 12,69 \\
\hline $45-\Pi$ & 17320 & 8,5 & 52,77 & - & - & 4,42 & 115,0 & 52,27 \\
\hline $46-\Pi$ & 19575 & 8,2 & 45,62 & - & - & 1,49 & 99,70 & 45,32 \\
\hline $47-\Pi$ & 19081 & 8,2 & 14,47 & - & - & 2,28 & 31,18 & 14,17 \\
\hline $49-\Pi$ & 17599 & 8,0 & - & 19,20 & 29,0 & - & - & - \\
\hline $51-\Pi$ & 26602 & 7,7 & - & 6,08 & 118,5 & - & - & - \\
\hline
\end{tabular}

Note: DOC-dissolved organic carbon; $O D$ - oxygen demand; $C O D$ - chemical oxygen demand; $B O D$ - biochemical oxygen demand; FA-fulvic acid; HA-humic acid. 
Средние значения показателей РОВ в целом на уровне с озерными водами, только с бо́лышим интервалом. Достаточно высокие содержания $\mathrm{C}_{\text {орг }}$ от 2,2 до 35,8 мг/л, немного выше, чем в озерных, показатель БПК $_{5}$ - от 0,66 до 3,15 мгО $/$ л, немного ниже показатель ХПК - от 8,6 до 22,7 мгО/л, единожды достигая в p. Черновой Нарык (1-p) максимума - 126,5 мгО/л (у моста через реку). Отношение фульвокислот к гуминовым кислотам такое же, как и для озерных вод. При этом содержание ФК меняется в широком интервале от 4,8 до 78,8 мг/л, а ГК в узком - от 0,3 до 1,5 мг/л.

Подземные воды. Отличаются значительным интервалом разброса как по химическому составу вод, так и по органическому. Поэтому были рассмотрены отдельно в соответствии с вертикальной гидрогеохимической зональностью по объектам с разным водообменом.

Зона активного водообмена находится в верхней части геологического разреза, сложена рыхлыми, преимущественно четвертичными или интенсивно трещиноватыми, юрскими отложениями. Здесь до глубины ориентировочно 150-200 м распространены пресные (с соленостью от 0,4 до 0,8 г/л) воды, по химическому составу гидрокарбонатные кальциевые, в основном нейтральные, реже слабощелочные (рН от 7,0 до 8,4).

Показатели РОВ занижены по сравнению с поверхностными водами: $\mathrm{C}_{\text {орг }}$ от 1,1 до 7,9 мг/л (в среднем в 3 раза меньше, чем для речных и озерных), ПО от 0,1 до 4,0 мгО/л (в 3-10 раз меньше), ХПК от 3,5 до 31,9 мгО/л (в 1,5 раза меньше). Показатель БПК от 0,1 до 1,5 $\mathrm{MrO}_{2} /$ л (на уровне с поверхностными).

Несмотря на то, что концентрации ФК варьируют в узком диапазоне от 2,0 до 14,8 мг/л, в процентном соотношении от общего содержания гуминовых веществ разброс достаточно широкий - от 68,8 до $100 \%$, т. е. превалирование ФК над ГК не всегда подавляющее, хотя в целом, конечно, значимое. Содержания ГК максимально достигают значений до 2,0 мг/л.

Зона замедленного водообмена находится ниже, на глубине от 100-200 до 1200 м, по нашим данным, а возможно, и ниже. Сложена песчаными средневерхнепермскими угленосными, частично эффузивноосадочными триасовыми безугольными отложениями. Воды уже солоноватые и соленые (от 0,8 до 26,6 г/л), нейтральные и щелочные (рН от 7,1 до 8,7), по составу уже гидрокарбонатные натриевые (содовые). В составе водорастворенного газа повсеместно превалирует метан.

Данные воды более всех обогащены органическим веществом: $\mathrm{C}_{\text {орг }}$ изменяется от 4,0 до 52,8 мг/л (в среднем в 10 раз больше вод зоны активного водообмена, в 2-2,5 раза больше поверхностных), ПО от 0,3 до 19,2 мгО/л (в среднем в 2-5 раз больше пресных), ХПК от 7,2 до 160,5 мгО/л (в среднем в 2 раза больше), БПК от 0,7 до $4,4 \mathrm{MrO}_{2} /$ л (в среднем в 2-5 раза больше).

Отношение ФК к ГК стабильное, фульвокислоты составляют от 90,6 до 99,3 \%, в концентрациях изменяясь от 2,0 до 150,0 мг/л. Концентрации гуминовых кислот значительно меньше, от 0,2 до 8,2 мг/л.

\section{Обсуждение результатов}

Таким образом, как поверхностные, так и подземные воды Нарыкско-Осташкинской площади Кузнецкого бассейна обогащены POB: $\mathrm{C}_{\text {орг }}$ от 1,1 до 52,8 мг/л, ПО от 0,1 до 19,6 мГО/л, ХПК от 4,5 до $160,5 \mathrm{мГО/л,} \mathrm{БПК} \mathrm{от} 0,02$ до 4,4 $\mathrm{M \Gamma O}_{2} /$ л. В составе гуминовых веществ превалируют фульвокислоты от 2 до 115 мг/л, затем гуминовые кислоты в концентрациях от 0,2 до 8,2 мг/л.

При этом наиболее однородными по органическому (как и по химическому) составу оказались речные и озерные воды, где такие показатели, как $\mathrm{C}_{\text {орг, }}$ ПО, БПК, ХПК, колеблются в узком интервале значений, как и пропорции ФК к ГК (85-95 и 5-15 \% соответственно). Подземные воды, наоборот, отличаются крайне неоднородным составом. Для зоны активного водообмена характерны наименьшие показатели РОВ и наибольший разброс отношения ФК и ГК (69-100 и 0-31\% соответственно). Уменьшение органических веществ в подземных водах по сравнению с поверхностными закономерно в силу отсутствия источника. В то время как для вод зоны замедленного водообмена характерны наибольшие показатели РОВ и снова узкий разброс значений ФК к ГК (90-99 и 1-10\% соответственно). Здесь уже оказывает влияние наличия угольных пластов.

Сравнение химического и органического составов вод показало неоднозначные результаты. При закономерном увеличении солености вод от поверхностных к подземным и далее по глубине все показатели, а также ФК и ГК ведут себя следующим образом: сначала снижаются до минерализации вод 1 г/л, а в более соленых водах (от 10 г/л и выше) снова увеличиваются и даже уже превышают показатели поверхностных. Некоторые зависимости РОВ от солености представлены на рис. 2.

При этом влияние угля в зоне замедленного водообмена сказывается не только на концентрации в водах $\mathrm{POB}$, но и на увеличении общей минерализации вод по схеме $\mathrm{C}_{\text {уголь }} \rightarrow \mathrm{CO}_{2} \rightarrow \mathrm{HCO}_{3}{ }^{-} \rightarrow \mathrm{M}$. Это обеспечило интересный парадокс, когда содовые воды достигают минерализации 27 г/л и выше, что нехарактерно для них. Более детальный механизм этого процесса описан в работах $[39,40]$.

Каких-либо связей показателей РОВ от макрокомпонентов вод $\left(\mathrm{HCO}_{3}^{-}, \mathrm{Cl}^{-}, \mathrm{SO}_{4}{ }^{2-}, \mathrm{Ca}^{2+}, \mathrm{Mg}^{2+}, \mathrm{Na}^{+}, \mathrm{K}^{+}\right)$ не обнаружено, в некоторых случаях лишь отмечается увеличение концентраций железа от ПО [41].

От кислотно-щелочных условий среды какой-либо закономерности в изменении РОВ не прослеживается (рис. 3). Это связано с достаточно сложными закономерностями изменения самого $\mathrm{pH}$ вод в районе [40]. В поверхностных водах он меняется от 6,7 (болото) до 9,4 (пруд-отстойник), в подземных - от 7,0 до 8,7. Здесь основные два противоположных процесса: гидролиз алюмосиликатов с выделением группы $\mathrm{OH}^{-}$и нейтрализация органическими кислотами щелочи. Какой из процессов преобладает в системе, туда и сместиться баланс кислота-щелочь. 

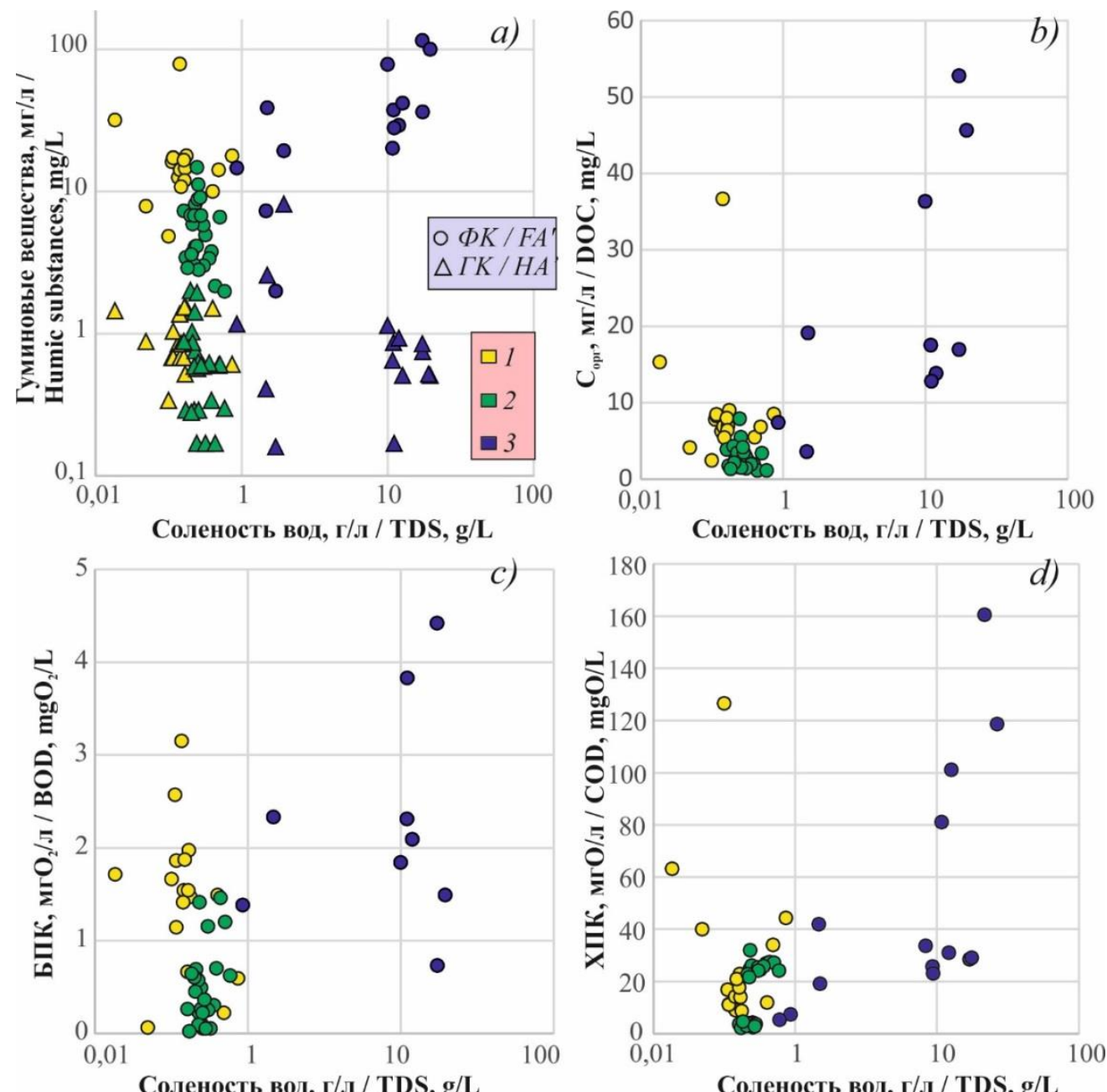

Рис. 2. Изменения содержаний растворенного органического вещества от солености вод: а) гуминовые вещества, b) растворенный органический углерод, с) биохимическое потребление кислорода, d) химическое потребление кислорода. 1 - поверхностные воды; 2, 3 - подземные воды (2-активного водообмена, 3 -замедленного водообмена)

Fig. 2. Dependences of soil organic matter concentration on water salinity: a) humic substances, b) dissolved organic carbon, c) biochemical oxygen demand, $d)$ chemical oxygen demand. 1 - surface water; 2, 3 - groundwater $(2-$ with intensely fractured rocks, 3 - zone of damped fracturing)
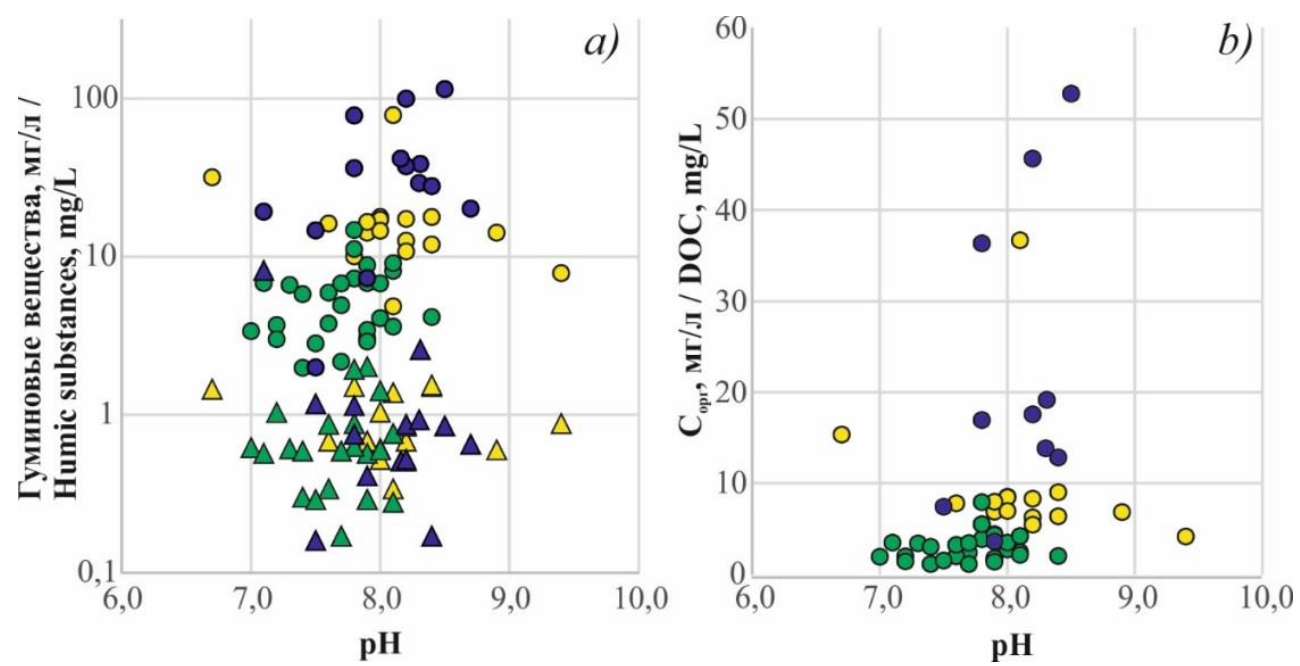

Рис. 3. Изменения содержаний растворенного органического вещества от рН вод: а) гуминовые вещества, b) растворенный органический углерод. Условные обозначения - на рис. 2

Fig. 3. Dependences of soil organic matter concentration on water $p H:$ a) humic substances, b) dissolved organic carbon. Symbols are in the Fig. 2 


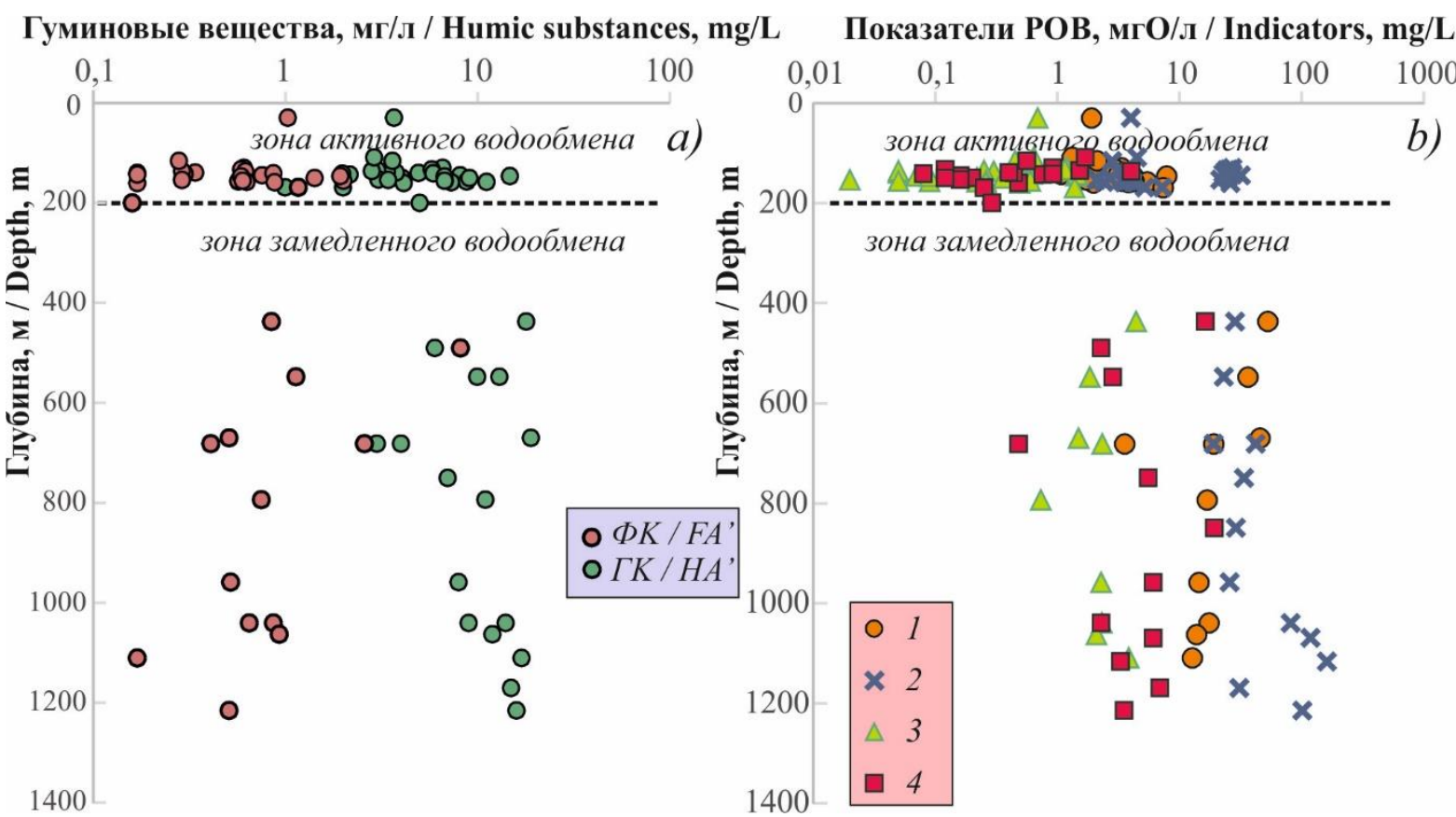

Рис. 4. Изменения содержаний растворенного органического вещества от глубины вод: а) гуминовые вещества, b) показатели: 1 - растворенный органический углерод (мг/л), 2 - перманганатная окисляемость, 3 -химическое потребление кислорода, 4 - биохимическое потребление кислорода

Fig. 4. Dependences of soil organic matter concentration on depth of water: a) humic substances, b) indicators: 1 dissolved organic carbon ( $\mathrm{mg} / \mathrm{L}) ; 2$ - oxygen demand, 3 - chemical oxygen demand, 4 - biochemical oxygen demand

С глубиной в подземных водах органическое вещество изменяется также сложным образом. До 200 м разброс значений по всем показателям достаточно широкий (рис. 4) и каких-либо четких закономерностей (увеличение/уменьшение) не обнаружено. Ниже 400 м, в зоне замедленного водообмена угленосных отложений, РОВ увеличиваются на 1-2 порядка, но в интервале глубин 400-1200 м также четких закономерностей не прослеживается.

Несмотря на то, что связь органического состава вод с химическим, с кислотно-щелочными условиями и глубинами циркуляции вод не столь однозначна, рассматривать необходимо все же их совместно. Объясняются такие разбросы наложением сразу нескольких процессов, иногда прямо противоположных, и сложными процессами преобразования органического вещества. Более детальные исследования помогут лучше разобраться в особенностях распределения РОВ в природных водах региона. Пока получены первые результаты и предпринята попытка их интерпретации.

\section{Заключение}

Проведенные исследования по растворенному органическому веществу в природных водах территории Нарыкско-Осташкинской площади показали следующие первые результаты:

1. РОВ в природных водах контролируются такими параметрами, как концентрация органического углерода, перманганатная окисляемость, химическое потребление кислорода, биохимическое потребление кислорода. Количественно определяют некоторые группы веществ, наиболее распространенные в данном случае гуминовые вещества: фульво- и гуминовые кислоты. Как правило, в поверхностных водах растворенных органических веществ больше, чем в подземных. Однако в Кузбассе на исследуемой площади, где широко развиты угольные пласты, подземные воды ниже 400 м также обогащены органикой.

2. В составе гуминовых веществ во всех исследованных водах преимущественно распространены фульвокислоты, от 69 до 100 \%, в количественном отношении от 2 до 115 мг/л. Гуминовые кислоты имеют подчиненное значение до $31 \%$, в количественном отношении от 0,2 до 8,2 мг/л.

3. Минимальные и максимальные значения всех показателей органических веществ относятся к подземным водам. Меньше всего органики в зоне активного водообмена, для этих вод характерен также относительно неоднородный состав гумусовых веществ. Для зоны замедленного водообмена характерны наибольшие показатели растворенных органических веществ и относительно однородный состав фульво- и гуминовых кислот.

4. Речные и озерные воды отличаются более однотипным составом гуминовых веществ и органических показателей и даже между собой сильно не отличаются при различии в химическом составе вод.

5. Каких-либо закономерностей изменения РОВ от солености вод, химического состава, $\mathrm{pH}$ и глубины не было четко выявлено, что связано с наложением нескольких процессов, в том числе слож- 
ными процессами преобразования органического вещества.

6. Это первый этап в изучении особенностей распределения растворенных органических веществ на территории, который позволил определить фоновые содержания органики, а в дальнейшем использовать эти данные при изучении формирования химического состава вод, например, при рас-

\section{СПИСОК ЛИТЕРАТУРЫ}

1. Лаврик Н.Л., Муллоев Н.У. Влияние концентрации гуминовых кислот в водных растворах на структуру их макромолекул // Химия в интересах устойчивого развития. - 2006. - Т. 14. № 2. - С. 379-390.

2. Левшина С.И. Органическое вещество поверхностных вод бассейна Среднего и Нижнего Амура. - Владивосток: Дальнаука, 2010. - 145 с.

3. Гумусовые вещества в поверхностных водах Украины / П.Н. Линник, Я.С. Иваненко, Р.П. Линник, В.А. Жежеря // Экологическая химия. - 2013. - Т. 22. - № 2. - С. 74-90.

4. Формирование состава органических веществ в малых озерах Западной Сибири / Л.П. Паничева, Т.И. Моисеенко, Т.А. Кремлева, С.С. Волкова // Вестник Тюменского государственного университета. Экология и природопользование. 2015. - T. 1. - № 1 (1). - C. 151-163.

5. Poturay V.A., Kompanichenko V.N. Composition and distribution of saturated hydrocarbons in the thermal waters and vapor-water mixture of the Mutnovskii geothermal field and Uzon caldera, Kamchatka // Geochemistry International. - 2019. - V. 57. № 1. - P. 74-82.

6. Organic trace contaminants in fresh natural waters from the drainage basins of Tom' and upper Ob' rivers / A.E. Kontorovich, S.L. Shvartsev, N.M. Rasskazov, V.A. Zuev, Yu.P. Turov // Geochemistry International. - 2000. - V. 38. - № 5. - P. 480-490.

7. The ecological and geochemical state of the water in the middle course of the $\mathrm{Ob}$ river / S.L. Shvartsev, O.G. Savichev, L.F. Frizen, G.G. Vertman, R.F. Zarubina, N.G. Nalivaiko, N.G. Trifonova, V.V. Yankovskii, Yu.P. Turov // Water Resources. - 1996. V. 23. - № 6. - P. 673-682.

8. Гузняева М.Ю., Туров Ю.П. Состав органических примесей в природных водах территории с нефтегазовыми месторождениями // Иерархические материалы: разработка и приложения для новых технологий и надежных конструкций: Тезисы докладов Международного симпозиума. - Томск: Изд-во ТГУ, 2018. - С. 807.

9. Динамика растворенного неорганического углерода и потоков CO2 между водой и атмосферой в главном русле реки Обь / И.И. Пипко, С.П. Пугач, О.Г. Савичев, И.А. Репина, Н.Е. Шахова, Ю.А. Моисеева, К.В. Барсков, В.И. Сергиенко, И.П. Семилетов // Доклады Академии наук. - 2019. - Т. 484. - № 6. C. 691-697.

10. Славинская Г.В., Селеменев В.Ф. Фульвокислоты природных вод. - Воронеж: Воронежский Государственный университет, 2001. $-165 \mathrm{c}$.

11. Новые данные о составе органических веществ в минеральных водах / Г.М. Шпейзер, А.И. Смирнов, В.А. Хуторянский и др. // Современные проблемы науки и образования. - 2006. № 2. - C. 62-64.

12. Curtis P.J., Adams H.E. Dissolved organic matter quantity and quality from freshwater and saltwater lakes in east-central Alberta // Biogeochemistry. - 1995. - V. 30. - P. 59-76.

13. Dissolved organic carbon and fluorescence in Lake Hovsgol: factors reducing humic content of the lake water / K. Hayakawa, T. Sekino, T. Yoshioka, M. Maruo, M. Kumagai // Limnology. 2003. - V. 4. - P. 25-33.

14. Polikreti K., Christofi des C. The role of humic substances in the formation of marble patinas under soil burial conditions // Physics and Chemistry of Minerals. - 2009. - V. 36. - P. 271-279. четах равновесий в системе вода - гумусовые вещества.

Работа выполнена при финансовой поддержке грантов РФФИ № 20-05-00127 и 19-05-00290 и проекта ФНИ СО РАН «Геологическая эволюиия системы вода-порода-газорганическое вещество (на примере отдельных районов Западно-Сибирского и Тунгусского артезианских бассейнов)». Авторы посвящают статью памяти профессора В.К. Попова.

15. Origins and bioavailability of dissolved organic matter in groundwater / Y. Shen, F.H. Chapelle, E.W. Strom, R. Benner // Biogeochemistry. - 2015. - V. 122. - P. 61-78.

16. Impact of natural organic matter and divalent cations on the stability of aqueous nanoparticles / Y. Zhang, Y. Chen, P. Westerhoff, J. Crittenden // Water Research. - 2009. - V. 43. P. 4249-4257.

17. Гаськова О.Л., Склярова О.А. Влияние природных органических кислот на отношение $\mathrm{Mg} / \mathrm{Ca}$ в донных осадках высокоминерализованных озер // Геология и геофизика. - 2013. Т. 54. - № 6. - С. 829-840.

18. Дину М.И. Сравнение комплексообразующих способностей фульвокислот и гуминовых кислот в водной среде с ионами железа и цинка // Водные ресурсы. - 2010. - Т. 37. - № 1. C. $65-69$

19. Взаимодействие катионов меди, цинка и марганца с бурыми углями и гуминовыми кислотами / С.И. Жеребцов, Н.В. Малышенко, Л.В. Брюховецкая, 3.Р. Исмагилов // Кокс и химия. $-2017 .-$ T. 10. - С. 29-35.

20. Лапин И.А., Красюков В.Н. Роль гумусовых веществ в процессах комплексообразования и миграции металлов в природных водах // Водные ресурсы. - 1986. - № 1. - С. 134-143.

21. Махарадзе Г.А. Формы миграции меди и гумусовых кислот в поверхностных водах: дис. ... кан. хим. наук. - М., 1984. $161 \mathrm{c}$.

22. Ephrai J.H., Allard B. Metal ion binding by humic substances in modelling in aquatic chemistry. - New York: World, 1997. $724 \mathrm{p}$.

23. Hirose K. Metal-organic matter interaction: ecological roles of ligands in oceanic DOM // Applied Geochemistry. - 2007. V. 22. - P. 1636-1645.

24. $\mathrm{Al}(\mathrm{III})$ and $\mathrm{Fe}$ (III) binding by humic substances in freshwaters and implications for trace metal speciation / E. Tipping, C. Rey-Castro, S.E. Bryan, J. Hamilton-Taylor // Geochimica et Cosmochimica Acta. - 2002. - V. 66. - № 18. - P. 3211-3224.

25. Xue H., Sigg L. Comparison of the complexation of $\mathrm{Cu}$ and $\mathrm{Cd}$ by humic or fulvic acids and by ligands observed in lake waters // Aquatic Geochemistry. - 1999. - V. 5. - P. 313-335.

26. Sholkovitz E.E., Copland D. The coagulation, solubility and adsorption properties of $\mathrm{Fe}, \mathrm{Mn}, \mathrm{Cu}, \mathrm{Ni}, \mathrm{Cd}, \mathrm{Co}$ and humic acids in river water // Geochimica et Cosmochimica Acta. - 1981. V. 45. - P. 181-189.

27. Питьевая вода. Гигиенические требования к качеству воды централизованных систем питьевого водоснабжения. Контроль качества. Гигиенические требования к обеспечению безопасности систем горячего водоснабжения: Санитарноэпидемиологические правила и нормативы. СанПиН 2.1.4.1074-01. - Введ.2002. - 01.01. - М.: Минздрав России, 2001. $-23 \mathrm{c}$

28. Предельно допустимые концентрации (ПДК) химических веществ в воде водных объектов хозяйственно-питьевого и культурно-бытового водопользования: Гигиенические нормативы. ГН 2.1.5.1315-03. - Введ.2003. - 15.06. - М.: Минздрав России, 2003. - 154 с

29. Вода питьевая. Общие требования к организации и методам контроля качества: Госстандарт России. ГОСТ Р 51232-98. Введ.1999. - 01.07. - М.: Изд-во стандартов, 1999. - 18 с.

30. Крайнов С.Р., Рыженко Б.Н., Швец В.М. Геохимия подземных вод. Теоретические, прикладные и экологические аспекты. М.: Изд-во ЦентрЛитНефтеГаз, 2012. - 672 с. 
31. Орлов Д.С., Бирюкова О.Н., Суханова Н.И. Органическое вещество почв Российской Федерации. - М.: Наука, 1996. $256 \mathrm{c}$.

32. Кузнецкий бассейн - крупнейшая сырьевая база промысловой добычи метана из угольных пластов / А.М. Карасевич, В.Т. Хрюкин, Б.М. Зимаков, Н.Г. Матвеенко, С.С. Золотых, В.Г. Натура, Т.С. Попова. - М.: Изд-во Академии горных наук, 2001. $-64 \mathrm{c}$.

33. Гидрогеология СССР. Кемеровская область и Алтайский край / под ред. М.А. Кузнецовой, О.В. Постниковой. - М.: Изд-во Недра, 1972. - T. XVII. - 398 c.

34. Покровский Д.С., Плевако Г.А. Гидрогеохимические условия зоны пологих брахиструктур Кузбасса на примере Ерунаковского угленосного района // Известия Томского политехнического института. - 1975. - Т. 297. - С. 57-63.

35. Попов В.К. Особенности формирования и использование подземных вод угленосных образований Кузбасса (на примере центральных и южных районов): автореф. дис.... канд. геол.минерал. наук - Томск, 1975. $-23 \mathrm{c}$.

36. Рогов Г.М., Попов В.К. Гидрогеология и катагенез пород Кузбасса. - Томск: Изд-во Томского университета, 1985. $191 \mathrm{c}$.

37. Гидрогеология Ерунаковского района Кузбасса в связи с проблемой образования ресурсов и добычи угольного метана /
С.Л. Шварцев, В.Т. Хрюкин, Е.В. Домрочева, К.И. Кузеванов, Н.М. Рассказов, Т.С. Попова, О.Е. Лепокурова, Е.В. Швачко // Геология и геофизика. - 2006. - Т. 47. - № 7. - С. 881-891.

38. Домрочева Е.В., Лепокурова О.Е., Сизиков Д.А. Геохимическая характеристика подземных вод Нарыкско-Осташкинской площади (Кузбасс) // Известия Томского политехнического университета. - 2014. - Т. 325. - № 2. - С. 94-101.

39. Аномальный состав изотопов углерода в подземных щелочных водах Кузбасса / С.Л. Шварцев, О.Е. Лепокурова, Е.В. Домрочева, В.А. Пономарчук, Д.А. Сизиков // Доклады академии наук. - 2016. - Т. 469. - № 6. - С. 724-728.

40. Лепокурова, О.Е. Содовые подземные воды юга Кузбасса: изотопно-химические особенности и условия формирования // Геохимия. - 2018. - № 9. - С. 904-919.

41. Лепокурова О.Е., Домрочева Е.В. Микрокомпонентный состав природных вод Нарыкско-Осташкинской площади (Кузбасс) // Подземные воды Востока России: материалы Всероссийского совещания по подземным водам Востока России (XXII Совещание по подземным водам Сибири и Дальнего Востока с международным участием). - Новосибирск: ИПЦ НГУ, 2018. - C. 302-307.

Поступила 29.02.2020 2.

\section{Информация об авторах}

Лепокурова O.E., доктор геолого-минералогических наук, заведующая лабораторией, Томский филиал Института нефтегазовой геологии и геофизики им. А.А. Трофимука СО РАН; доцент отделения геологии Инженерной школы природных ресурсов Национального исследовательского Томского политехнического университета. Домрочева E.B., кандидат геолого-минералогических наук, научный сотрудник, Томский филиал Института нефтегазовой геологии и геофизики им. А.А. Трофимука СО РАН. 
UDC 556.314

\title{
HUMIC SUBSTANCES IN NATURAL WATER OF THE NARYKSKO-OSTASHKINSKAYA AREA (KUZBASS)
}

\author{
Olesya E. Lepokurova1,2, \\ LepokurovaOY@ipgg.sbras.ru
}

\author{
Evgeniya V. Domrocheva1, \\ DomrochevaYV@ipgg.sbras.ru \\ 1 Tomsk Branch of Trofimuk Institute of Petroleum-Gas Geology and Geophysics of SB RAS, \\ 4, Academichesky avenue, Tomsk, 634055, Russia. \\ 2 National Research Tomsk Polytechnic University, \\ 30, Lenin avenue, Tomsk, 634050, Russia.
}

\begin{abstract}
Relevance. Dissolved organic matter almost always presents in waters and plays an important role in formation of their chemical composition, while until recently it has received little attention. For the Kuznetsk Basin, the study of dissolved organic matter is very important due to the presence of coal deposits, which determines the regional specifics of the loads on water systems.

The aim of the research is to study the dissolved organic matter distribution in the surface and groundwaters of the region.

Methods. Chemical and organic composition of water was determined by standard methods in the Research Laboratory for Hydrogeochemistry of Tomsk Polytechnic University: dissolved organic carbon - by the method of high-temperature catalytic oxidation, oxygen demand, chemical oxygen demand, biochemical oxygen demand - by titration methods. Fulvic acid and humic acid were determined by the titration method to account dichromate consumed for the fulvic and humic acid carbon oxidation.

Results and conclusions. The paper introduces the data on dissolved organic matter indicators and fulvic acid and humic acid concentrations in river, lake and ground waters of the Kuzbass Naryksko-Ostashkinskaya area. It was shown that fulvic acids prevail, from 69 to $100 \%$, in all waters in composition of humic substances. The humic ones have a subordinate significance. Groundwater in zones with intensely fractured rocks is distinguished by the minimum values of all dissolved organic matter indicators (dissolved organic carbon, oxygen demand, chemical oxygen demand, biochemical oxygen demand) and relatively heterogeneous humic substances composition. River and lake waters have more homogeneous humic substances composition and narrow dissolved organic matter range values, despite differences in chemical composition and $\mathrm{pH}$. For groundwater in zone of damped fracturing circulating within the coal deposits at depths of 400-1200 m, the highest dissolved organic matter indicators and relatively homogeneous fulvic and humic acid composition are characteristic. At the first stage of the research, there is no relationship between the organic matter concentration and the salinity and all the waters chemical composition, $\mathrm{pH}$ and depth.
\end{abstract}

\section{Key words:}

Fulvic acid, humic acid, natural water, coal deposits, Kuzbass.

The research was financially supported by the FSR SB RAS project and by the RFBR grants no. 20-05-00127 and 19-05-00290. The authors devote an article to the memory of Professor V.K. Popov.

\section{REFERENCES}

1. Lavrik N.L., Mulloev N.U. Effect of the concentration of humic acids in aqueous solutions on the structure of their macromolecules. Khimiya $v$ interesakh ustoychivogo razvitiya, 2006, vol. 14, no. 2, pp. 379-390. In Rus.

2. Levshina S.I. Organicheskoe veshchestvo poverhnostnykh vod basseyna Srednego i Nizhnego Amura [Organic matter of surface waters of the Middle and Lower Amur basin]. Vladivostok, Dalnauka Publ., 2010. 145 p.

3. Linnik P.N., Ivanenko Ya.S., Linnik R.P., Zhezherya V.A. Gumusovye veshchestva $\mathrm{v}$ poverkhnostnykh vodakh Ukrainy [Humus substances in surface water of Ukraine]. Ekologicheskaya khimiya, 2013, vol. 22, no. 2, pp. 74-90.

4. Panicheva L.P., Moiseenko T.I., Kremleva T.A., Volkova S.S Formation of the composition of organic substances in small lakes of Western Siberia. Vestnik Tyumenskogo gosudarstvennogo universiteta. Ekologiya i prirodopolzovanie, 2015, vol. 1, no. 1 (1), pp. 151-163. In Rus.

5. Poturay V.A., Kompanichenko V.N. Composition and distribution of saturated hydrocarbons in the thermal waters and vapor-water mixture of the Mutnovskii geothermal field and Uzon caldera, Kamchatka. Geochemistry International, 2019, vol. 57, no. 1, pp. 74-82.

6. Kontorovich A.E., Shvartsev S.L., Rasskazov N.M., Zuev V.A. Turov Yu.P. Organic trace contaminants in fresh natural waters from the drainage basins of Tom' and upper Ob' rivers. Geochemistry International, 2000, vol. 38, no. 5, pp. 480-490.

7. Shvartsev S.L., Savichev O.G., Frizen L.F., Vertman G.G., Zarubina R.F., Nalivaiko N.G., Trifonova N.G., Yankovskii V.V., Turov Yu.P. The ecological and geochemical state of the water in the middle course of the Ob river. Water Resources, 1996, vol. 23, no. 6, pp. 673-682.

8. Guznyaeva M.Yu., Turov Yu.P. Sostav organicheskikh primesey v prirodnykh vodakh territorii $\mathrm{s}$ neftegazovymi mestorozhdeniyami [Composition of organic impurities in natural waters of the territory with oil and gas fields]. Tezisy dokladov mezhdunarodnogo simpoziuma. Ierarkhicheskie materialy: razrabotka i prilozhenie dlya novykh tekhnology i nadezhnykh konstrukrsiy [Proceedings of the symposium. Hierarchical materials: development and application for new techniques and reliable constructions]. Tomsk, TGU Publ., 2018. pp. 807.

9. Pipko I.I., Pugach S.P., Savichev O.G., Repina I.A., Shakhova N.E., Moiseeva Yu.A., Barskov K.V., Sergienko V.I., Semiletov I.P. Dynamics of dissolved inorganic carbon and $\mathrm{CO} 2$ fluxes between the water and the atmosphere in the main channel of the $\mathrm{Ob}$ river. Doklady Chemistry, 2019, vol. 484, P. 2, pp. 52-57. In Rus.

10. Slavinskaya G.V., Selemenev V.F. Fulvokisloty prirodnykh vod [Fulvic acids of natural waters]. Voronezh, Voronezh State University Publ., 2001. 165 p.

11. Sfeyzer G.M., Smirnov A.I., Khutoryanskiy V.A. Novye dannye o sostave organicheskikh veshchestv v mineralnykh vodakh [New 
data on composition of organic substances in mineral waters]. Sovremennye problemy nauki i obrazovaniya, 2006, no. 2, pp. 62-64.

12. Curtis P.J., Adams H.E. Dissolved organic matter quantity and quality from freshwater and saltwater lakes in east-central Alberta. Biogeochemistry, 1995, vol. 30, pp. 59-76.

13. Hayakawa K., Sekino T., Yoshioka T., Maruo M., Kumagai M. Dissolved organic carbon and fl uorescence in Lake Hovsgol: factors reducing humic content of the lake water. Limnology, 2003, vol. 4, pp. $25-33$.

14. Polikreti K., Christofi des C. The role of humic substances in the formation of marble patinas under soil burial conditions. Physics and Chemistry of Minerals, 2009, vol. 36, pp. 271-279.

15. Shen Y., Chapelle F.H., Strom E.W., Benner R. Origins and bioavailability of dissolved organic matter in groundwater. Biogeochemistry, 2015, vol. 122, pp. 61-78.

16. Zhang Y., Chen Y., Westerhoff P., Crittenden J. Impact of natural organic matter and divalent cations on the stability of aqueous nanoparticles. Water Research, 2009, vol. 43, pp. 4249-4257.

17. Gaskova O.L., Sklyarova O.A. Influence of natural organic acids on the $\mathrm{Mg} / \mathrm{Ca}$ ratio in the bottom sediments of highly mineralized lakes. Russian Geology and Geophysics, 2013, vol. 54, no. 6, pp. 637-645. In Rus.

18. Dinu M.I. Comparison of complexing ability of fulvic and humic acids in the aquatic environment with iron and zinc ions. Water Resources, 2010, vol. 37, no. 1, pp. 65-69.

19. Zherebtsov S.I., Malyshenko N.V., Bryukhovetskaya L.V., Ismagilov Z.R. Interaction of copper, zinc, and manganese cations with lignite and humic acids. Coke and Chemistry, 2017, vol. 60, no. 10, pp. 397-403. In Rus.

20. Lapin I.A., Krasyukov V.N. Rol gumusovykh veshchestv v processakh kompleksoobrazovaniya i migratsii metallov v prirodnykh vodakh [The role of humus substances in the complex formation and migration of metals in natural waters]. Vodnye resursy, 1986, no. 1, pp. 134-143.

21. Makharadze G.A. Formy migratsii medi i gumusovykh kislot $v$ poverkhnostnykh vodakh. Dis. Kand. nauk [Forms of migration of copper and humic acids in surface waters. Cand. Diss.]. Moscow, 1984. $161 \mathrm{p}$.

22. Ephrai J.H., Allard B. Metal ion binding by humic substances in modelling in aquatic chemistry. New York, World, 1997. $724 \mathrm{p}$.

23. Hirose K. Metal-organic matter interaction: ecological roles of ligands in oceanic DOM. Applied Geochemistry, 2007, vol. 22, pp. 1636-1645.

24. Tipping E., Rey-Castro C., Bryan S.E., Hamilton-Taylor J. Al(III) and $\mathrm{Fe}$ (III) binding by humic substances in freshwaters and implications for trace metal speciation. Geochimica et Cosmochimica Acta, 2002, vol. 66, no. 18, pp. 3211-3224.

25. Xue H., Sigg L. Comparison of the complexation of $\mathrm{Cu}$ and $\mathrm{Cd}$ by humic or fulvic acids and by ligands observed in lake waters. Aquatic Geochemistry, 1999, vol. 5, pp. 313-335.

26. Sholkovitz E.E., Copland D. The coagulation, solubility and adsorption properties of $\mathrm{Fe}, \mathrm{Mn}, \mathrm{Cu}, \mathrm{Ni}, \mathrm{Cd}, \mathrm{Co}$ and humic acids in river water. Geochimica et Cosmochimica Acta, 1981, vol. 45, pp. 181-189.

27. Pitevaya voda. Gigienicheskie trebovaniya $k$ kachestvu vody tsentralizovannykh sistem pitevogo vodosnabzheniya. Kontrol kachestva. Gigienicheskie trebovaniya $k$ obespecheniyu bezopasnosti sistem goryachego vodosnabzheniya [Drinking water. Hygienic requirements for water quality of centralized drinking water supply systems. Quality control. Hygienic requirements for the security of hot water systems]. SanPiN 2.1.4.1074-01. Moscow, Minzdrav Rossii, 2001. 23 p.

28. Predelno-dopustimye kontsentratsii (PDK) khimicheskikh veshchestv $v$ vode vodnykh obektov khozyaystvenno-pitevogo i kulturno-bytovogo vodopolzovaniya [Maximum permissible concentrations (MPC) of chemicals in water of water bodies of drinking and cultural-domestic water use]. GN 2.1.5. 1315-03. Moscow, Minzdrav Rossii, 2003. 154 p.

29. Voda pitevaya gigienicheskie trebovaniya i kontrol za kachestvom [State Standard 51232-98. Drinking water: hygiene requirements and quality control]. GOST R 51232-98. Moscow, Izdatelstvo standartov, $1999.18 \mathrm{p}$.

30. Kraynov S.R., Ryzhenko B.N., Shvets V.M. Geokhimiya podzemnykh vod. Teoreticheskie, prikladnye i ekologicheskie aspekty [Geochemistry of groundwater. Theoretical, applied and environmental aspects]. Moscow, TsentrLitNefteGaz Publ., 2012. 672 p.

31. Orlov D.S., Biryukova O.N., Sukhanova N.I. Organicheskoe veshchestvo pochv Rossiyskoy Federatsii [Soil organic matter of the Russian Federation]. Moscow, Nauka Publ., 1996. 256 p.

32. Karasevich A.M., Khryukin V.T., Zimakov B.M., Matveenko N.G., Zolotykh S.S., Natura V.G., Popova T.S. Kuznetskiy basseyn krupneyshaya syrevaya baza promyslovoy dobychi metana iz ugolnykh plastov [Kuznetsk basin is the largest raw material base of commercial production of methane from coal deposits]. Moscow, Mining Academy Press, 2001. $64 \mathrm{p}$.

33. Gidrogeologiya SSSR. Kemerovskaya oblast i Altayskiy kray [Hydrogeology of USSR. Kemerovo Region and Altai Territory]. Eds. M.A. Kuznetsova, O.V. Postnikova. Moscow, Nedra Publ., 1972. Vol. 17, $398 \mathrm{p}$.

34. Pokrovskiy D.S., Plevako G.A. Gidrogeokhimicheskie usloviya zony pologikh brakhistruktur Kuzbassa na primere Erunakovskogo uglenosnogo rayona [Hydrogeochemical conditions of the zone of gentle brachistructure of Kuzbass on the example of the Yerunakovsky coal-bearing area]. Bulletin of the Tomsk Polytechnic Institute, 1975, vol. 297, pp. 57-63.

35. Popov V.K. Osobennosti formirovaniya $i$ ispolzovanie podzemnykh vod uglenosnykh obrazovaniy Kuzbassa (na primere centralnykh i yuzhnykh rayonov). Avtoreferat Dis. Kand. nauk [Features of formation and use of groundwater coal-bearing formations of Kuzbass (for example, the central and southern regions). Cand. Diss. Abstract]. Tomsk, 1975. 23 p.

36. Rogov G.M., Popov V.K. Gidrogeologiya i katagenez porod Kuzbassa [Hydrogeology and katagenesis rocks of Kuzbass]. Tomsk, Tomsk University Publ., 1985. 191 p.

37. Shvartsev S.L., Khryukin V.T., Domrocheva E.V., Kuzevanov K.I., Rasskazov N.M., Popova T.S., Lepokurova O.E., Shvachko E.V. Hydrogeology of the Erunakovo region of the Kuznetsk basin in the context of coal methane formation and mining. Russian Geology and Geophysics, 2006, vol. 47, no. 7, pp. 881-891. In Rus.

38. Domrocheva E.V., Lepokurova O.E., Sizikov D.A. Geochemical characterization of underground water of the NarykskoOstashkinskaya area (Kuzbass). Bulletin of the Tomsk Polytechnic University, 2014, vol. 325, no. 2, pp. 94-101. In Rus.

39. Shvartsev S.L., Lepokurova O.E., Domrocheva E.V., Ponomarchuk V.A., Sizikov D.A. Abnormal composition of carbon isotopes in underground alkaline waters of Kuzbass. Doklady Earth Sciences, 2016, vol. 469, no. 2, pp. 877-881. In Rus.

40. Lepokurova O.E. Sodic groundwaters in the Southern Kuznetsk basin: isotopic and chemical characteristics and genesis. Geochemistry International, 2018, vol. 56, no. 9, pp. 934-949.

41. Lepokurova O.E., Domrocheva E.V. Mikrokomponentny sostav prirodnykh vod Naryksko-Ostashkinskoy ploshchadi (Kuzbass) [Trace elements in nature water of Naryksko-Ostashkinskaya area (Kuzbass)]. Podzemnye vody Vostoka Rossii. Materialy Vserossiyskogo soveshchaniya po podzemnym vodam Vostoka Rossii (XXII Soveshchanie po podzemnym vodam Sibiri i Dalnego Vostoka s mezhdunarodnym uchastiem) [Underground waters in Russian East. Materials of the All-Russian meeting on underground waters of Russian East (XXII meeting on underground waters of Siberia and Far East with international participance)]. Novosibirsk, IPC NGU Publ., 2018. pp. 302-307.

Received: 29 February 2020.

\section{Information about the authors}

Olesya E. Lepokurova, Dr. Sc., head of laboratory, Tomsk Branch of Trofimuk Institute of Petroleum-Gas Geology and Geophysics of SB RAS; associate professor, National Research Tomsk Polytechnic University.

Evgeniya V. Domrocheva, Cand. Sc., researcher, Tomsk Branch of Trofimuk Institute of Petroleum-Gas Geology and Geophysics of SB RAS. 